Semin Hematol. 2013 April ; 50(2): 165-174. doi:10.1053/j.seminhematol.2013.03.030.

\title{
Telomere dynamics in mice and humans
}

\author{
Rodrigo T. Calado, M.D., Ph.D. ${ }^{1}$ and Bogdan Dumitriu, M.D. ${ }^{2}$ \\ ${ }^{1}$ Department of Internal Medicine, University of São Paulo at Ribeirão Preto School of Medicine, \\ Ribeirão Preto, SP, Brazil \\ ${ }^{2}$ Hematology Branch, National Heart, Lung, and Blood Institute, National Institutes of Health, \\ Bethesda, MD
}

\section{Abstract}

Telomeres are ribonucleoprotein structures capping the end of every linear chromosome. In all vertebrates, they are composed of TTAGGG repeats coated with specific protecting proteins. Telomeres shorten with each mitotic cell division, but telomerase, a reverse transcriptase, elongate telomeres in very specific cells, such as embryonic and adult stem cells. Although telomere sequence is identical in mice and humans and telomeres serve the same role of protecting chromosomes and genetic information from damage and erosion in both species, abnormalities in telomere maintenance and in telomerase function do not coincide in phenotype in humans and mice. The telomeres of most laboratory mice are 5 to 10 times longer than in humans, but their lifespan is 30 times shorter. Complete absence of telomerase has little expression in phenotype over several generations in mice, whereas heterozygosity for telomerase mutations in humans is sufficient to result in organ regeneration defect and cancer development. Patients with telomerase deficiency and very short telomeres may develop aplastic anemia, pulmonary fibrosis, or cirrhosis, whereas telomerase-null murine models display only modest hematopoietic deficiency and develop emphysema when exposed to cigarette smoke. In summary, telomerase deficiency in both humans and mice accelerate telomere shortening, but its consequences in the different organs and in the organism diverge, mainly due to telomere length differences.

\section{INTRODUCTION}

The evolution of chromosomes from circular to linear structures required the cell to develop mechanisms able to differentiate the "natural ends" of chromosomes from broken DNA and to overcome the inevitable DNA shortening during mitotic cell division. ${ }^{1}$ Telomeres are complex ribonucleoprotein structures that solve these problems; they are located at the extremities of linear chromosomes, are composed of hundreds to thousand hexameric DNA repeats (TTAGGG in the leading strand and CCCTAA in the lagging strand of vertebrates), and are coated by several specialized proteins (shelterin). Telomeres provide the solution to the two problems raised by linear chromosomes. First, as the DNA polymerase is unable to fully duplicate the $3^{\prime}$ end of the DNA strand during mitotic cell division, the newly

(C) 2013 Elsevier Inc. All rights reserved.

Correspondence: Rodrigo T. Calado, Department of Internal Medicine, University of São Paulo at Ribeirão Preto School of Medicine, Av. Bandeirantes, 3900, Bloco G, subsolo, HCRP - Lab. Hematologia, Ribeirão Preto, SP 14049-900 SP, Brazil, Tel.: +(55)(16) 3602-2294 - Fax: +(55)(16) 3633-6695, rtcalado@fmrp.usp.br.

Publisher's Disclaimer: This is a PDF file of an unedited manuscript that has been accepted for publication. As a service to our customers we are providing this early version of the manuscript. The manuscript will undergo copyediting, typesetting, and review of the resulting proof before it is published in its final citable form. Please note that during the production process errors may be discovered which could affect the content, and all legal disclaimers that apply to the journal pertain.

The authors have no financial conflict of interest to disclose. 
synthesized DNA strand is always shorter than the original template, culminating in chromosome shortening during mitosis - the end replication problem. ${ }^{2}$ The end replication problem results from DNA polymerase's requirement for a $3^{\prime}$ hydroxyl donor to initiate nucleotide polymerization, usually utilizing an RNA primer. For most DNA replication, after the DNA polymerase moves away from the primers and continues duplicating the DNA strand the RNA primer is released and its binding site is filled by polymerization, catalyzed by the polymerase present in the adjacent Okazaki fragment. However, at the very end of the chromosome, there is no adjacent Okazaki fragment, the empty space left by the RNA primer remains unfilled, and the newly synthesized DNA strand is shorter than the original DNA template at its $5^{\prime}$ end. With repeated mitotic cell divisions, the chromosomes become progressively shorter. Loss of genetic information as a result of erosion is avoided in part by the structure of the termini, telomeres, which are long DNA sequences that do not encode for specific genes. Telomere attrition is the molecular mechanism responsible for the "Hayflick limit". 3 Hayflick had observed that human cells in culture were unable to duplicate indefinitely in the Petri dish and stop dividing after 40 to 60 divisions, when they enter cell replicative senescence; cells remain viable and metabolically active with very short telomeres, but they are incapable of proliferation. When telomeres reach critically short lengths - when cells reach the Hayflick limit—-they signal proliferation arrest by activating cellular pathways, mainly activating the p53 tumor suppressor protein.,

The telomere structure, hexanucletoide repeats with associated bound proteins collectively termed shelterin, also provide stability to the ends of chromosomes, preventing their recognition by the DNA repair machinery as unwanted DNA breaks and precluding end-toend fusion of chromosomes. ${ }^{6}$ When telomeres are too short, they cannot adequately protect the ends of chromosomes. When the amount of shelterin proteins is low due to short telomeres, they do not adequately inhibit the DNA repair machinery and unwanted telomere processing may occur. Under these circumstances, at least six repair mechanisms may be recruited to operate on telomeres: ATM (ataxia telangiectasia mutated) and ATR (ataxia telangiectasia and Rad3 related) signaling, classical non-homologous end-joining (NHEJ), alternative-NHEJ, homologous recombination, and resection. ${ }^{7}$ End-to-end fusion of the chromosomes, aneuploidy, and non-reciprocal translocations are all markers of chromosome instability.

Telomeres also can be actively repaired. Cells with high proliferative capacity, such as embryonic and adult tissue-specific stem cells, elongate eroded telomeres by the catalytic function of telomerase, a reverse transcriptase that adds hexameric telomeric repeats to the $3^{\prime}$ end of the DNA leading strand. Telomerase holoenzyme is essentially composed of a reverse transcriptase (TERT), an RNA component (TERC) that serves as a template for TERT function, dyskerin (encoded by $D K C 1$ ), and associated proteins, which help holoenzyme assembly and stability. ${ }^{8}$ Telomerase expression is repressed in most mature cells in humans but activated in embryonic and adult stem cells.

That telomeres shorten with cell division is applicable beyond the behavior of an individual cell, as telomere length is the biomarker best associated with organism aging. ${ }^{9}$ With aging, telomeres invariably shorten: in human umbilical cord blood, leukocytes' telomere lengths are in average about 10-kb long and shorten approximately 50 to 60 bp/year.

Telomere dynamics has been linked to physiologic stem cell maintenance and to pathophysiology, as in tissue regeneration failure and cancer (Fig. 1). In this review, we will describe how murine and human telomere biology coincide or diverge and the usefulness of animal models to study telomeropathies. Although the basic biology of telomeres is the same in both species, their characteristics, maintenance, and function are different and 
abnormalities in telomere homeostasis may result in divergent manifestations in these species.

\section{TELOMERES, AGING, AND LONGEVITY}

As telomeres erode with cell division, serving as a "mitotic clock" for the proliferative history of a cell or tissue and resulting in cell senescence and apoptosis, telomere biology has been postulated as the molecular mechanism for physiologic and pathologic aging. ${ }^{10}$

In mice, specific serum proteins (CRAMP, stathmin, EF-1a, and chitinase) are elevated in late generation telomerase "knockout" mice. ${ }^{11}$ However, these changes only occur in aging mice, which are telomerase-deficient for several generations and have developed very short telomeres. Old "wild-type" laboratory mice do not have higher serum levels for these proteins, nor do telomerase-deficient animals in the first generations after gene "knockout". Elderly humans with age-associated illnesses also present higher plasma levels of the human homologues of these proteins when compared to young adults, and the plasma levels of dysfunctional telomere-associated proteins also are higher in humans with chronic disorders associated with aging, such as cirrhosis and myelodysplastic syndrome.

Mice deficient for telomerase and with short telomeres (after successive interbreeding of "knockout" animals) also show hypotrophic intestinal villi, lower blood cells counts, and reduced bone marrow cellularity ${ }^{9}$. These findings only weakly associate with the physiology of human aging: marrow cellularity and, to a minimal extent, blood cell counts are hematologic features of the elderly. However, telomere length does not correlate with blood counts in healthy elderly humans. ${ }^{12}$ In very special and highly selected circumstances, pathologic conditions may trigger telomeres to mediate the process and force a correlation; for instance, in humans with chronic heart failure, short telomeres associate with anemia, ${ }^{13}$ but it does not reflect the general older population. Likewise, hypotrophic intestinal villi observed in mice with short telomeres do not parallel age-related changes in the human intestine, as villus height and surface epithelium appear not to vary with age. ${ }^{14}$

Cardiovascular diseases are characteristic of human aging and telomeres have been implicated in this connection. Older individuals with shorter telomeres are at higher risk of dying from cardiovascular disease ${ }^{15}$ and one epidemiologic study found that individuals with shorter telomeres had a higher risk of developing coronary artery disease, which was alleviated by statins. ${ }^{16}$ Individuals with clinical or subclinical atherosclerosis have shorter telomeres than do sex- and age-matched healthy controls. ${ }^{17-19}$ Short telomeres also associate with environmental risk factors commonly associated with cardiovascular disease, such as obesity, smoking, ${ }^{20,21}$ and sedentary life style. ${ }^{22}$ However, atherosclerosis is not a feature of telomerase-deficient mice; on the contrary, short telomeres limit atheroma progression in these animals. ${ }^{23}$

Telomerase-deficient mice with dysfunctional telomeres also usually display abnormal mitochondrial biogenesis and function, decreased gluconeogenesis, and cardiomyopathy 24 and reversal of telomerase expression and function restores these functions to normal, implicating telomeres in the development of disorders associated with aging. However, these are pathological features not usually observed in humans with defective telomerase and short telomeres. ${ }^{9,25,26}$

Aging is a process and longevity is a measurement. Telomere length has been proposed by many investigators as a potential biomarker for longevity (or lifespan) in humans, mice, and other organisms. In one study, telomerase "knockout" mice (deficient for telomerase RNA component) were interbred and the life expectancy of consecutive generations assessed. ${ }^{27}$ As the offspring of "knockout" animals inherit both deficient telomerase and short telomeres 
from their parents, telomeres are shorter with each generation. In this experiment, median survival inversely correlated with "knockout" generations, and with successive generations offspring showed shorter lifespans in comparison to their parents. The correlation between telomere length and life expectancy also has been investigated in aging humans, with some conflicting results. In a landmark study, humans older than 60 years of age who had longer telomeres had better median survival than those with shorter telomeres. ${ }^{15}$ Telomeres were measured in peripheral blood leukocytes collected at enrolment and outcomes were assesses prospectively. Peculiarly, the major causes of death associated with short telomeres were infections and cardiovascular disease. However, this association was not confirmed in another prospective study in humans aged 73 to 101 years. ${ }^{28}$

Although there are similarities between mice and humans for association between telomere attrition and aging, there are fundamental differences that preclude simple biologic comparisons by analogy. First, association does not mean causality; telomere erosion may be an outcome rather than the cause of aging. Second, laboratory mice have a life expectancy of 18 to 24 months and they mature and age during this time frame, while their telomeres are 50 to 150-kilobase long. In sharp contrast, human life expectancy at birth varies today from 70 to 80 years, but our telomeres are 5 to 10 times shorter than in mice, ranging from about 5 to 6 kilobases in those older than 60 years to 10 to 12 kilobases in the newborn. ${ }^{9}$ This comparison itself challenges the hypothesis that telomere length may drive aging or predict lifespan either in humans or mice. Murine telomeres do not serve as a mitotic clock for replicative aging, as primary cells constitutively express telomerase, in contrast to humans, in whom telomeres play a part in replicative senescence and telomerase expression is repressed. ${ }^{5,29}$ In humans, the Hayflick limit is determined by telomere shortening, but murine fibroblasts stop dividing after 10 to 15 population doublings in vitro, before any appreciable sign of telomere erosion. ${ }^{29}$ That murine telomeres are significantly longer than human telomeres makes it more difficult to interpret the current data correlating telomere length and longevity, whether in humans or in laboratory mice. In mammals, telomere length inversely correlates with lifespan and telomerase expression inversely correlates with body mass, ${ }^{30}$ indicating that telomeres serve different purposes in different species and that telomere elongation and telomerase activation may represent an adaptive evolutionary advantage of small short-lived mammals in exchange for energy-expensive oxidative DNA damage mechanisms. ${ }^{30}$ Even within the rodent order, telomerase expression inversely correlates with body mass; while in large rodents (e.g., capybara, beaver) telomerase function is inhibited, small rodents (mouse) constitutively express telomerase in somatic cells, subverting replicative senescence. ${ }^{31}$

Third, the variation in telomere length in laboratory mice from a given strain or generation of telomerase-deficient animals is very narrow. In contrast, humans display broad variability in telomere length at any age (Figure 1); healthy 10-year-old human individuals in the lower end for telomere length overlap with healthy subjects at age 60 or older. This high variability in telomere length in a given age range observed in humans precludes a more stringent understanding of telomere as a marker or mechanism of aging, although, for a given individual, telomeres constantly shorten with time. ${ }^{9}$

Finally, humans are observed in the "wild" and telomere length regulation is subjected to environmental factors that may increase telomere loss, such as infection, diet, inflammation, pollution, smoking, ultraviolet light, oxygen concentration, reactive oxygen species, whereas laboratory mice are kept in sterile, highly controlled environment with balanced and invariable diet in the animal facility, which may hamper the effects of intricate interactions among factors acting on telomere erosion and elongation. For instance, reactive oxygen species, which accumulate over time, directly damage DNA, including telomeres, and accelerate telomere erosion. ${ }^{32}$ Human induced pluripotent stem (iPS) cells cultured in 
hypoxic conditions display higher telomerase expression levels and increased telomere elongation as compared to iPS cells cultured in atmospheric oxygen. ${ }^{33}$ In addition, the ingestion levels of marine omega- 3 fatty acids appears to modulate the rate of telomere loss in humans. ${ }^{34}$

\section{TELOMERES AND DISEASE}

In humans, defects in telomerase function result in progressive telomere shortening, which clinically manifests as severe diseases that are often fatal. X-linked dyskeratosis congenita is the prototypical human telomere disease; it is characterized by mucocutaneous dystrophy in boys associated with aplastic anemia, the most common cause of death, usually in the first decade of life. ${ }^{35}$ Patients with dyskeratosis congenita commonly have other organs affected, mainly the lungs (pulmonary fibrosis), ${ }^{36}$ liver (cirrhosis), ${ }^{26}$ esophagus (stricture), ${ }^{35,37}$ and a proclivity for cancer development, especially head and neck squamous cell carcinomas and leukemia. ${ }^{38}$ All these features are the result of excessive telomere shortening, and patients' telomere lengths consistently are below the first percentile for age-matched healthy subjects. ${ }^{39}$ Short telomeres signal the p53 pathway and inhibit hematopoietic stem and progenitor cell proliferation, hamper liver and lung regeneration, and induce chromosome instability, thus facilitating cancer initiation. X-linked dyskeratosis congenita is caused by mutations in the $D K C 1$ gene, located in the $\mathrm{X}$ chromosome and encoding dyskerin, an essential component of the telomerase complex. ${ }^{40}$ Telomerase activity is patients' primary cells are very low, but not completely absent, as patients are hemizygous for the mutation. The mother, however, who carries the mutation, does not usually have short telomeres, and the mutation-carrying chromosome may be inactivated.

More common in the clinic are cases with mutations in the reverse transcriptase (TERT) or in the RNA component of telomerase (TERC). ${ }^{41}$ In these cases, mutations are heterozygous, meaning that patients retain a wild-type allele and telomerase function is approximately $50 \%$ of that observed in healthy subjects and the clinical presentation is milder, usually affecting only one organ. Patients have short telomeres and telomerase deficiency occurs by haploinsufficiency. The most commonly affected organs are the bone marrow (as frank aplastic anemia and a broad range of more limited marrow failure syndromes), ${ }^{42}$ lungs (as pulmonary fibrosis and perhaps more general insufficiency), ${ }^{36,43}$ and liver (as cirrhosis and a variety of related hepatic dysfunction syndromes). ${ }^{44,45}$ As telomerase function is only partially defective with TERT and TERC mutations, they act as risk factors rather than disease determinants; individuals may carry a telomerase mutation, but not develop disease. In addition, the clinical syndrome usually appears later in life, as opposed to the early presentation in dyskeratosis congenita, and patients inherit both the mutation and short telomeres from the affected parent. Given this complex inheritance pattern, telomeres are shorter at each generation and disease may manifest earlier or more intensely in the offspring, a phenomenon called disease anticipation. ${ }^{46}$

Murine models deficient for telomerase have been developed with outcomes diverse from the pathology of human syndromes. ${ }^{47-49}$ In hypomorphic mutant $D k c 1$ mice, telomeres remain stable in length for two generations and telomere shortening is only evident after $\mathrm{G} 4,{ }^{47}$ as opposed to humans with $D K C 1$ mutations, in which telomere shortening appears at early age in the affected hemizygous patient. ${ }^{40}$ In mice, signs of bone marrow failure are subtle, usually with less than $10 \%$ reduction in marrow cellularity, there are no obvious changes in peripheral blood counts, and the number of hematopoietic stem and progenitor cells is mildly reduced. ${ }^{47}$ In humans, bone marrow cellularity usually is intense, with less than $10 \%$ cellularity, patients present with severe pancytopenia, and the number of hematopoietic progenitors in the marrow is dramatically reduced. ${ }^{41}$ In the hypomorphic $D k c 1$ mouse model, ribosome function is significantly impaired with reduction in the rRNA 
pseudourydilation and decreased accumulation of mature rRNA forms. ${ }^{47}$ Abnormal ribosomal function appears to play a major role in the clinical manifestations of dyskerin deficiency in mice, especially in cancer formation, ${ }^{50}$ whereas in humans, ribosomal dysfunction has a marginal contribution - if any-to the pathophysiology of the telomeropathies ${ }^{9}$ (although implicated in a variety of other human marrow failure syndromes). ${ }^{51,52}$ Mutations in shelterin components (TINF2), causing abnormal telomere uncapping but with unchanged telomerase holoenzyme function, including dyskerin, also cause dyskeratosis congenita that is clinically indistinguishable from cases caused by $D K C 1$ mutations, except by the inheritance pattern (autosomal dominant versus X-linked), ${ }^{53}$ indicating that disturbances in ribosomal RNA processing are likely peripheral to the pathophysiology of the human disease. Indeed, the most severe forms of dyskeratosis congenita, the Hoyeraal-Hreidarsson syndrome and Revesz syndrome, in which the nervous system and the retina also are affected, are caused by mutations in genes that are not part of the telomerase complex, but play important role in telomere biology and maintenance (TINF2, CTC1, RTEL1). ${ }^{53-55}$

Telomerase reverse transcriptase (Tert)-deficient and telomerase RNA component (Terc)deficient mice also have been engineered ${ }^{48,49}$ Although either $m$ Tert or $m$ Terc is completely knocked out in the murine model, animals are viable and fertile and do not show any evidence of cell regeneration deficiency or organ failure until later generations $\left(>5^{\text {th }}\right.$ generation). Even when these changes occur, they are mild; bone marrow cellularity is above $80 \%$ (as opposed to below 10\% in humans) and reductions in peripheral blood cell counts are modest, far from causing anemia, infection, or bleeding in the mouse. ${ }^{27}$

Apparently, animals become infertile before visceral target organs become significantly affected. In humans heterozygosity and haploinsuffiency are sufficient for organ failure to develop (bone marrow failure, pulmonary fibrosis, cirrhosis, cancer), whereas for organs to become defective in mice, telomerase has to be completely abolished. For the bone marrow to become clinically hypoplastic in the mouse model, mTerc complete deficiency has to be engineered along with Pot $1 b$ (a shelterin protein) deficiency, a complex gene haplotype not observed in humans. ${ }^{56}$ Animals that are heterozygous for $m$ Tert deficiency, for instance, may survive apparently healthy over multiple generations; ${ }^{57} \mathrm{mTerc}$-deficiency heterozygosity at 17 generations does not measurably affect marrow, lung, liver, and testes function.

While humans with telomerase deficiency can develop pulmonary fibrosis, this phenotype is not observed in the mouse model. Surprisingly, the opposite is observed in the mouse, as telomerase activity appears to be required for pulmonary fibrosis to occur upon bleomycin challenge.$^{58}$ Mice who are deficient for $m$ Tert develop less lung fibrosis than wild-type mice. When mTerc "knockout" mice are forced to inhale smoke, they develop emphysema, an obstructive lung disease, rather than fibrosis, a restrictive lung disease. ${ }^{59}$

In summary, the murine models available for telomerase deficiency do not accurately recapitulate the tissue damage and regeneration deficiency often observed in patients with telomere diseases. For organs to be affected in the mouse, telomere dysfunction has to be engineered, multiple genes deleted, and telomerase activity completely abolished, in contrast to humans, in which telomerase haploinsufficiency alone can produce a clinical phenotype.

\section{TELOMERES AND CANCER}

Almost 100 years ago, Boveri postulated chromosomal instability as the initiating pathogenic event in oncogenesis. ${ }^{60}$ Consistent with this hypothesis, most cancers have an aneuploid genome as well as qualitative chromosome changes, as deletions or translocations. Telomere attrition has been proposed as a mechanism for the loss or gain of chromosomes. 
In the absence or decrease of telomerase activity, mutation rates increase as a result of terminal chromosome deletions and repeated cycles of break-fusion-bridge rearrangements. ${ }^{61}$

In a National Cancer Institute review of 50 cases of classic dyskeratosis congenita, the risks of cancer development was increased (overall, about 11 times as high as in the general population), especially for skin, head and neck squamous-cell carcinomas, anorectal cancers, and acute myeloid leukemia. ${ }^{38}$ In patients with acquired aplastic anemia, telomere length of leukocytes is the major predictor of "clonal evolution": patients with telomere length in the lowest quartile have the highest risk of developing myelodysplastic syndrome, frequently associated with monosomy 7 and acute myeloid leukemia. ${ }^{62}$ Moreover, telomere-free ends of chromosomes and aneuploidy are apparent in patients' bone marrows in tissue culture years before clinical symptoms. ${ }^{63}$ Constitutional TERT mutations are detected in about $9 \%$ of acute myeloid leukemia patients and are strongly associated with the risk of cytogenetic abnormalities. ${ }^{64}$ In small studies, telomere length has also been associated with increased risk of leukemic transformation after chemotherapy and autologous hematopoietic-cell transplantation. ${ }^{65}$

Telomere length has been linked to many cancers in humans. The finding of short telomeres in colorectal cancer cells suggested that telomere loss contributes to oncogenesis and genetic instability of the malignant cell. ${ }^{66}$ Patients with ulcerative colitis that developed cancer at a later stage of their disease have telomerase deficiency leading to telomere shortening as well as losses of chromosomes and anaphase bridges. ${ }^{67}$ Short telomeres and chromosomal instability associated with dysplastic changes occur in Barrett's esophagus, a chronic inflammatory condition often leading to esophageal cancer. ${ }^{45}$

A genome-wide scan of more than 30,000 patients of European ancestry with cancer and 45,000 controls showed an association between the TERT locus and 5 of 16 cancers in the list, including basal-cell cancer of the skin and cancers of the lung, bladder, prostate, and cervix. ${ }^{68}$ Lung cancer and TERT locus polymorphisms were associated in two cohorts, one large European population ${ }^{69}$ and one Chinese. ${ }^{70}$ Moreover, in the Chinese cohort the risk was also linked to short telomeres. Other associations include gliomas ${ }^{71}$ and renal-cell carcinoma. ${ }^{72}$ Interestingly, reports associate the same TERT locus polymorphisms from the large European cohort with relative resistance to and breast cancer ${ }^{73}$ but susceptibility for hepatocellular carcinoma. ${ }^{74}$ More recent reports show both inherited and acquired mutations in the TERT promoter region correlate with an increase in TERT expression level in over $70 \%$ of melanomas. ${ }^{75,76}$

The existing evidence from analysis of human malignancy and telomere biology also was tested in mouse models. Both Tert and Terc knockout mice were generated on the B6 background. ${ }^{48,49}$ In late-generation Terc-knockout mice, short telomeres caused chromosomal instability through end-to-end fusions. Apoptosis eliminated most of these cells, but they could be rescued if DNA damage was not adequately monitored. Thus, in $\mathrm{Terc}^{-1-}$ mice that are also deficient in $\mathrm{p53}$, a variety of cancers develop in association with nonreciprocal translocations, mimicking human malignant conditions. ${ }^{77,78}$ To further investigate the interaction of short telomeres, telomerase deficiency, and p53 in oncogenesis, several mouse models with various tumor suppressors genes were generated (Table 1). In some genetic predisposition models, inactivation of telomerase accelerated onset of cancers, as in $\mathrm{K5}-\mathrm{Trf}^{79}$ and $\mathrm{Atm}^{-/-} \mathrm{p53^{-/- }}$ double knockout model. ${ }^{80}$ Inactivation of telomerase in $\mathrm{Atm}^{-/-} \mathrm{p53^{-1- }}$ mice increased the incidence of thymic lymphomas, which showed a similar mutation pattern as occurs in human lymphomas. $\mathrm{Tert}^{-1-} \mathrm{Atm}^{-1-} \mathrm{p53^{+/ }}$ mice had almost complete inactivation of p53 in the tumor cells, suggestive of the potential oncogenic mechanism of inactivating p53 in setting of short telomeres Confirming the requirement for 
p53 deficiency for tumor initiation, $\mathrm{Atm}^{-1-} \mathrm{Tert}^{-1}$ mice with intact $p 53 \mathrm{had}$ a decrease of thymic lymphoma incidence and delayed onset. ${ }^{81} \mathrm{~A}$ few other cancer mouse models have displayed a decreased incidence of tumor formation on Tert $^{-1}$ background. ${ }^{82-84}$

These mouse models of oncogenesis led to the theory that telomerase deficiency operating initially as a pro-oncogenic pathway, likely through chromosomal instability, but continuous inactivation of telomerase in tumor cells would decrease tumor growth. One experimental example: Apc-mutated mice develop intestinal neoplasia, progressing quickly from microadenomas to macroadenomas. Inactivation of telomerase on this background increased microadenomas formation but decreased the progression rate to macroadenomas. ${ }^{85}$

CAST/EiJ mice are a murine strain with telomere lengths similar to those observed in humans. Inactivation of the telomerase complex genes on this genetic background yielded phenotypes that were closer to human diseases, and cancer developed with haploinsufficiency, not requiring complete inactivation of Terc or Tert genes. ${ }^{86,87}$ Analyses of different cancer predisposition models on this background may help to bridge the considerable gap between the human and mouse phenotypes and clearly establish the exact role of telomeres in various cancers.

\section{CONCLUSIONS}

In mammals, telomere length inversely correlates with lifespan whereas telomerase expression inversely correlates with body mass; short-lived species with small body mass, such as mice, evolved to have much longer telomeres and express telomerase at the expenses of abandoning a role of telomeres in replicative aging, as observed in humans. Thus, murine telomerase "knockout" models have been useful in identifying and characterizing the major basic biology of telomeres and telomerase, but in depth understanding of the part telomeres play in human aging and disease is more difficult to be extrapolated from the mouse. Additionally, there are clear discrepancies in the genomic responses to injury between humans and mice ${ }^{88}$ and there are environmental differences between the "urban wild" and the animal facility cage. Indeed, mouse models usually poorly mimic human conditions. ${ }^{88}$

Using telomerase as a therapeutic target, whether it will be telomerase inhibition in malignancies or telomerase stimulation in clinical situations caused by telomere erosion (aplastic anemia, myelodysplasia, pulmonary fibrosis, hepatic cirrhosis) will ultimately need to be validated in human-based models. Novel approaches including deep-sequencing techniques ${ }^{89}$, reprogramming of mature somatic cells into pluripotency state (iPS cells) $)^{33}$ may permit modeling human telomere disorders ex vivo and overcome the limitations imposed by the mouse model.

\section{Acknowledgments}

Supported in part by FAPESP (RTC) and the NIH Intramural Research Program (BD).

\section{References}

1. Blackburn EH. Switching and signaling at the telomere. Cell. 2001; 106:661-73. [PubMed: 11572773]

2. Olovnikov AM. Principle of marginotomy in template synthesis of polynucleotides. Dokl Akad Nauk SSSR. 1971; 201:1496-9. [PubMed: 5158754]

3. Hayflick L, Moorhead PS. The serial cultivation of human diploid cell strains. Exp Cell Res. 1961; 25:585-621. [PubMed: 13905658]

4. Collado M, Blasco MA, Serrano M. Cellular senescence in cancer and aging. Cell. 2007; 130:22333. [PubMed: 17662938] 
5. Shay JW, Wright WE. Senescence and immortalization: role of telomeres and telomerase. Carcinogenesis. 2005; 26:867-74. [PubMed: 15471900]

6. de Lange T. Protection of mammalian telomeres. Oncogene. 2002; 21:532-40. [PubMed: 11850778]

7. Sfeir A, de Lange T. Removal of shelterin reveals the telomere end-protection problem. Science. 2012; 336:593-7. [PubMed: 22556254]

8. Cohen SB, Graham ME, Lovrecz GO, Bache N, Robinson PJ, Reddel RR. Protein composition of catalytically active human telomerase from immortal cells. Science. 2007; 315:1850-3. [PubMed: 17395830]

9. Calado RT, Young NS. Telomere diseases. N Engl J Med. 2009; 361:2353-65. [PubMed: 20007561]

10. Aubert G, Lansdorp PM. Telomeres and aging. Physiol Rev. 2008; 88:557-79. [PubMed: 18391173]

11. Jiang H, Schiffer E, Song Z, et al. Proteins induced by telomere dysfunction and DNA damage represent biomarkers of human aging and disease. Proc Natl Acad Sci USA. 2008; 105:11299_ 304. [PubMed: 18695223]

12. Mollica L, Fleury I, Belisle C, Provost S, Roy DC, Busque L. No association between telomere length and blood cell counts in elderly individuals. J Gerontol A Biol Sci Med Sci. 2009; 64:9657. [PubMed: 19435952]

13. Wong LS, Huzen J, van der Harst P, et al. Anaemia is associated with shorter leucocyte telomere length in patients with chronic heart failure. European journal of heart failure. 2010; 12:348-53. [PubMed: 20335352]

14. Lipski PS, Bennett MK, Kelly PJ, James OF. Ageing and duodenal morphometry. Journal of clinical pathology. 1992; 45:450-2. [PubMed: 1597527]

15. Cawthon RM, Smith KR, O'Brien E, Sivatchenko A, Kerber RA. Association between telomere length in blood and mortality in people aged 60 years or older. Lancet. $2003 ; 361: 393-5$. [PubMed: 12573379]

16. Brouilette SW, Moore JS, McMahon AD, et al. Telomere length, risk of coronary heart disease, and statin treatment in the West of Scotland Primary Prevention Study: a nested case-control study. Lancet. 2007; 369:107-14. [PubMed: 17223473]

17. Samani NJ, Boultby R, Butler R, Thompson JR, Goodall AH. Telomere shortening in atherosclerosis. Lancet. 2001; 358:472-3. [PubMed: 11513915]

18. Benetos A, Gardner JP, Zureik M, et al. Short telomeres are associated with increased carotid atherosclerosis in hypertensive subjects. Hypertension. 2004; 43:182-5. [PubMed: 14732735]

19. Aviv A. Genetics of leukocyte telomere length and its role in atherosclerosis. Mutat Res. 2012; 730:68-74. [PubMed: 21600224]

20. Valdes AM, Andrew T, Gardner JP, et al. Obesity, cigarette smoking, and telomere length in women. Lancet. 2005; 366:662-4. [PubMed: 16112303]

21. Mirabello L, Huang WY, Wong JY, et al. The association between leukocyte telomere length and cigarette smoking, dietary and physical variables, and risk of prostate cancer. Aging Cell. 2009; 8:405-13. [PubMed: 19493248]

22. Cherkas LF, Hunkin JL, Kato BS, et al. The association between physical activity in leisure time and leukocyte telomere length. Archives of internal medicine. 2008; 168:154-8. [PubMed: 18227361]

23. Poch E, Carbonell P, Franco S, Diez-Juan A, Blasco MA, Andres V. Short telomeres protect from diet-induced atherosclerosis in apolipoprotein E-null mice. FASEB journal: official publication of the Federation of American Societies for Experimental Biology. 2004; 18:418-20. [PubMed: 14688198]

24. Sahin E, Colla S, Liesa M, et al. Telomere dysfunction induces metabolic and mitochondrial compromise. Nature. 2011; 470:359-65. [PubMed: 21307849]

25. Savage SA, Bertuch AA. The genetics and clinical manifestations of telomere biology disorders. Genetics in medicine: official journal of the American College of Medical Genetics. 2010; 12:753-64. [PubMed: 21189492]

26. Calado RT, Regal JA, Kleiner DE, et al. A spectrum of severe familial liver disorders associate with telomerase mutations. PLoS One. 2009; 4:e7926. [PubMed: 19936245] 
27. Armanios M, Alder JK, Parry EM, Karim B, Strong MA, Greider CW. Short telomeres are sufficient to cause the degenerative defects associated with aging. Am J Hum Genet. 2009; 85:823-32. [PubMed: 19944403]

28. Bischoff C, Petersen HC, Graakjaer J, et al. No association between telomere length and survival among the elderly and oldest old. Epidemiology. 2006; 17:190-4. [PubMed: 16477260]

29. Wright WE, Shay JW. Telomere dynamics in cancer progression and prevention: fundamental differences in human and mouse telomere biology. Nat Med. 2000; 6:849-51. [PubMed: 10932210]

30. Gomes NM, Ryder OA, Houck ML, et al. Comparative biology of mammalian telomeres: hypotheses on ancestral states and the roles of telomeres in longevity determination. Aging Cell. 2011; 10:761-8. [PubMed: 21518243]

31. Gorbunova V, Seluanov A. Coevolution of telomerase activity and body mass in mammals: from mice to beavers. Mech Ageing Dev. 2009; 130:3-9. [PubMed: 18387652]

32. von Zglinicki T, Saretzki G, Ladhoff J, d'Adda di Fagagna F, Jackson SP. Human cell senescence as a DNA damage response. Mech Ageing Dev. 2005; 126:111-7. [PubMed: 15610769]

33. Winkler T, Hong SG, Decker JE, et al. Defective telomere elongation and hematopoiesis from telomerase-mutant aplastic anemia IPScs. The Journal of Clinical Investigation. 2013 in press.

34. Farzaneh-Far R, Lin J, Epel ES, Harris WS, Blackburn EH, Whooley MA. Association of marine omega-3 fatty acid levels with telomeric aging in patients with coronary heart disease. JAMA. 2010; 303:250-7. [PubMed: 20085953]

35. Dokal I. Dyskeratosis congenita in all its forms. Br J Haematol. 2000; 110:768-79. [PubMed: 11054058]

36. Armanios MY, Chen JJ, Cogan JD, et al. Telomerase mutations in families with idiopathic pulmonary fibrosis. N Engl J Med. 2007; 356:1317-26. [PubMed: 17392301]

37. Jonassaint NL, Guo N, Califano JA, Montgomery EA, Armanios M. The gastrointestinal manifestations of telomere-mediated disease. Aging Cell. 2012

38. Alter BP, Giri N, Savage SA, Rosenberg PS. Cancer in dyskeratosis congenita. Blood. 2009; 113:6549-57. [PubMed: 19282459]

39. Alter BP, Baerlocher GM, Savage SA, et al. Very short telomere length by flow fluorescence in situ hybridization identifies patients with dyskeratosis congenita. Blood. 2007; 110:1439-47. [PubMed: 17468339]

40. Heiss NS, Knight SW, Vulliamy TJ, et al. X-linked dyskeratosis congenita is caused by mutations in a highly conserved gene with putative nucleolar functions. Nat Genet. 1998; 19:32-8. [PubMed: 9590285]

41. Calado RT. Telomeres and marrow failure. Hematology Am Soc Hematol Educ Program. 2009:338-43. [PubMed: 20008219]

42. Yamaguchi H, Calado RT, Ly H, et al. Mutations in TERT, the gene for telomerase reverse transcriptase, in aplastic anemia. N Engl J Med. 2005; 352:1413-24. [PubMed: 15814878]

43. Tsakiri KD, Cronkhite JT, Kuan PJ, et al. Adult-onset pulmonary fibrosis caused by mutations in telomerase. Proc Natl Acad Sci USA. 2007; 104:7552-7. [PubMed: 17460043]

44. Calado RT, Brudno J, Mehta P, et al. Constitutional telomerase mutations are genetic risk factors for cirrhosis. Hepatology. 2011; 53:1600-7. [PubMed: 21520173]

45. Hartmann D, Srivastava U, Thaler M, et al. Telomerase gene mutations are associated with cirrhosis formation. Hepatology. 2011; 53:1608-17. [PubMed: 21520174]

46. Vulliamy T, Marrone A, Szydlo R, Walne A, Mason PJ, Dokal I. Disease anticipation is associated with progressive telomere shortening in families with dyskeratosis congenita due to mutations in TERC. Nat Genet. 2004; 36:447-9. [PubMed: 15098033]

47. Ruggero D, Grisendi S, Piazza F, et al. Dyskeratosis congenita and cancer in mice deficient in ribosomal RNA modification. Science. 2003; 299:259-62. [PubMed: 12522253]

48. Chiang YJ, Hemann MT, Hathcock KS, et al. Expression of telomerase RNA template, but not telomerase reverse transcriptase, is limiting for telomere length maintenance in vivo. Mol Cell Biol. 2004; 24:7024-31. [PubMed: 15282303] 
49. Blasco MA, Lee HW, Hande MP, et al. Telomere shortening and tumor formation by mouse cells lacking telomerase RNA. Cell. 1997; 91:25-34. [PubMed: 9335332]

50. Yoon A, Peng G, Brandenburger Y, et al. Impaired control of IRES-mediated translation in Xlinked dyskeratosis congenita. Science. 2006; 312:902-6. [PubMed: 16690864]

51. Ebert B, Lipton JM. Diamond Blackfan anemia and ribosome biogenesis: introduction. Semin Hematol. 2011; 48:73-4. [PubMed: 21435502]

52. Ellis SR, Gleizes PE. Diamond Blackfan anemia: ribosomal proteins going rogue. Semin Hematol. 2011; 48:89-96. [PubMed: 21435505]

53. Savage SA, Giri N, Baerlocher GM, Orr N, Lansdorp PM, Alter BP. TINF2, a component of the shelterin telomere protection complex, is mutated in dyskeratosis congenita. Am J Hum Genet. 2008; 82:501-9. [PubMed: 18252230]

54. Walne A, Bhagat T, Kirwan M, et al. Mutations in the telomere capping complex in bone marrow failure and related syndromes. Haematologica. 2012

55. Ballew BJ, Yeager M, Jacobs K, et al. Germline mutations of regulator of telomere elongation helicase 1, RTEL1, in Dyskeratosis congenita. Hum Genet. 2013

56. Hockemeyer D, Palm W, Wang RC, Couto SS, de Lange T. Engineered telomere degradation models dyskeratosis congenita. Genes Dev. 2008; 22:1773-85. [PubMed: 18550783]

57. Chiang YJ, Calado RT, Hathcock KS, Lansdorp PM, Young NS, Hodes RJ. Telomere length is inherited with resetting of the telomere set-point. Proc Natl Acad Sci USA. 2010; 107:10148-53. [PubMed: 20479226]

58. Liu T, Chung MJ, Ullenbruch M, et al. Telomerase activity is required for bleomycin-induced pulmonary fibrosis in mice. J Clin Invest. 2007; 117:3800-9. [PubMed: 18008008]

59. Alder JK, Guo N, Kembou F, et al. Telomere length is a determinant of emphysema susceptibility. American journal of respiratory and critical care medicine. 2011; 184:904-12. [PubMed: 21757622]

60. Boveri, T. Concerning the origin of malignant tumours. Cold Spring Harbor, NY: Cold Spring Harbor Laboratory Press and The Company of Biologists; 2008.

61. Hemann MT, Hackett J, A IJ, Greider CW. Telomere length, telomere-binding proteins, and DNA damage signaling. Cold Spring Harb Symp Quant Biol. 2000; 65:275-9. [PubMed: 12760041]

62. Scheinberg P, Cooper JN, Sloand EM, Wu CO, Calado RT, Young NS. Association of telomere length of peripheral blood leukocytes with hematopoietic relapse, malignant transformation, and survival in severe aplastic anemia. JAMA. 2010; 304:1358-64. [PubMed: 20858879]

63. Calado RT, Cooper JN, Padilla-Nash HM, et al. Short telomeres result in chromosomal instability in hematopoietic cells and precede malignant evolution in human aplastic anemia. Leukemia. 2012; 26:700-7. [PubMed: 22005790]

64. Calado RT, Regal JA, Hills M, et al. Constitutional hypomorphic telomerase mutations in patients with acute myeloid leukemia. Proc Natl Acad Sci USA. 2009; 106:1187-92. [PubMed: 19147845]

65. Chakraborty S, Sun CL, Francisco L, et al. Accelerated telomere shortening precedes development of therapy-related myelodysplasia or acute myelogenous leukemia after autologous transplantation for lymphoma. J Clin Oncol. 2009; 27:791-8. [PubMed: 19124806]

66. Hastie ND, Dempster M, Dunlop MG, Thompson AM, Green DK, Allshire RC. Telomere reduction in human colorectal carcinoma and with ageing. Nature. 1990; 346:866-8. [PubMed: 2392154]

67. O'Sullivan JN, Bronner MP, Brentnall TA, et al. Chromosomal instability in ulcerative colitis is related to telomere shortening. Nat Genet. 2002; 32:280-4. [PubMed: 12355086]

68. Rafnar T, Sulem P, Stacey SN, et al. Sequence variants at the TERT-CLPTM1L locus associate with many cancer types. Nat Genet. 2009; 41:221-7. [PubMed: 19151717]

69. McKay JD, Hung RJ, Gaborieau V, et al. Lung cancer susceptibility locus at 5p15.33. Nat Genet. 2008; 40:1404-6. [PubMed: 18978790]

70. Hosgood HD 3rd, Cawthon R, He X, Chanock S, Lan Q. Genetic variation in telomere maintenance genes, telomere length, and lung cancer susceptibility. Lung Cancer. 2009; 66:15761. [PubMed: 19285750] 
71. Shete S, Hosking FJ, Robertson LB, et al. Genome-wide association study identifies five susceptibility loci for glioma. Nat Genet. 2009; 41:899-904. [PubMed: 19578367]

72. Chen M, Ye Y, Yang H, et al. Genome-wide profiling of chromosomal alterations in renal cell carcinoma using high-density single nucleotide polymorphism arrays. Int J Cancer. 2009; 125:2342-8. [PubMed: 19521957]

73. Savage SA, Chanock SJ, Lissowska J, et al. Genetic variation in five genes important in telomere biology and risk for breast cancer. British journal of cancer. 2007; 97:832-6. [PubMed: 17848914]

74. Zhang C, Tian YP, Wang Y, Guo FH, Qin JF, Ni H. hTERT rs2736098 genetic variants and susceptibility of hepatocellular carcinoma in the Chinese population: a case-control study. Hepatobiliary \& pancreatic diseases international: HBPD INT. 2013; 12:74-9. [PubMed: 23392802]

75. Horn S, Figl A, Rachakonda PS, et al. TERT Promoter Mutations in Familial and Sporadic Melanoma. Science. 2013

76. Huang FW, Hodis E, Xu MJ, Kryukov GV, Chin L, Garraway LA. Highly Recurrent TERT Promoter Mutations in Human Melanoma. Science. 2013

77. Chin L, Artandi SE, Shen Q, et al. p53 deficiency rescues the adverse effects of telomere loss and cooperates with telomere dysfunction to accelerate carcinogenesis. Cell. 1999; 97:527-38. [PubMed: 10338216]

78. Artandi SE, Chang S, Lee SL, et al. Telomere dysfunction promotes non-reciprocal translocations and epithelial cancers in mice. Nature. 2000; 406:641-5. [PubMed: 10949306]

79. Blanco R, Munoz P, Flores JM, Klatt P, Blasco MA. Telomerase abrogation dramatically accelerates TRF2-induced epithelial carcinogenesis. Genes Dev. 2007; 21:206-20. [PubMed: 17234886]

80. Maser RS, Choudhury B, Campbell PJ, et al. Chromosomally unstable mouse tumours have genomic alterations similar to diverse human cancers. Nature. 2007; 447:966-71. [PubMed: 17515920]

81. Qi L, Strong MA, Karim BO, Armanios M, Huso DL, Greider CW. Short telomeres and ataxiatelangiectasia mutated deficiency cooperatively increase telomere dysfunction and suppress tumorigenesis. Cancer Res. 2003; 63:8188-96. [PubMed: 14678974]

82. Siegl-Cachedenier I, Munoz P, Flores JM, Klatt P, Blasco MA. Deficient mismatch repair improves organismal fitness and survival of mice with dysfunctional telomeres. Genes Dev. 2007; 21:2234-47. [PubMed: 17785530]

83. Khoo CM, Carrasco DR, Bosenberg MW, Paik JH, Depinho RA. Ink4a/Arf tumor suppressor does not modulate the degenerative conditions or tumor spectrum of the telomerase-deficient mouse. Proc Natl Acad Sci USA. 2007; 104:3931-6. [PubMed: 17360455]

84. Feldser DM, Greider CW. Short telomeres limit tumor progression in vivo by inducing senescence. Cancer cell. 2007; 11:461-9. [PubMed: 17433785]

85. Rudolph KL, Millard M, Bosenberg MW, DePinho RA. Telomere dysfunction and evolution of intestinal carcinoma in mice and humans. Nat Genet. 2001; 28:155-9. [PubMed: 11381263]

86. Strong MA, Vidal-Cardenas SL, Karim B, Yu H, Guo N, Greider CW. Phenotypes in mTERT(+)/ $(-)$ and $\operatorname{mTERT}(-) /(-)$ mice are due to short telomeres, not telomere-independent functions of telomerase reverse transcriptase. Mol Cell Biol. 2011; 31:2369-79. [PubMed: 21464209]

87. Hao LY, Armanios M, Strong MA, et al. Short telomeres, even in the presence of telomerase, limit tissue renewal capacity. Cell. 2005; 123:1121-31. [PubMed: 16360040]

88. Seok J, Warren HS, Cuenca AG, et al. Genomic responses in mouse models poorly mimic human inflammatory diseases. Proc Natl Acad Sci USA. 2013

89. Welch JS, Ley TJ, Link DC, et al. The origin and evolution of mutations in acute myeloid leukemia. Cell. 2012; 150:264-78. [PubMed: 22817890] 


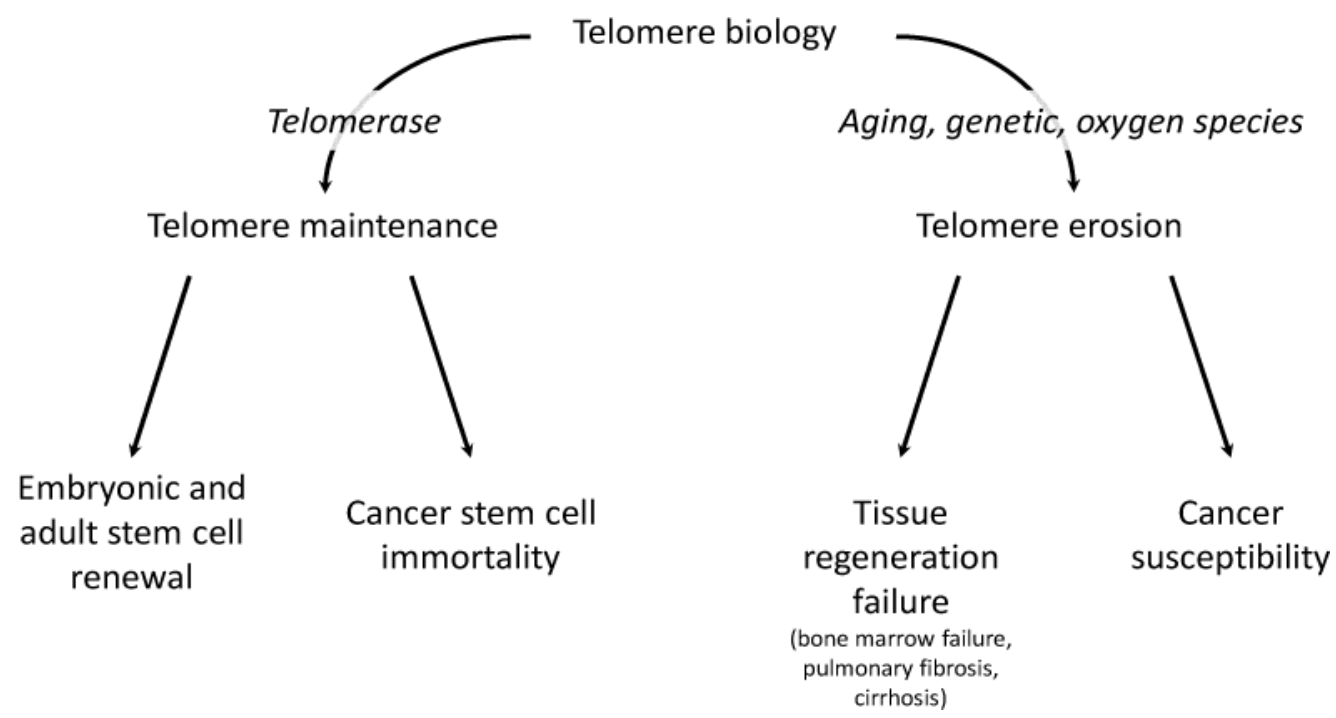

Figure 1.

Telomere length dynamics are determined in cells by a balance between telomere elongation provided by telomerase activity and telomere erosion due to mitotic division, telomere end processing and damage. Imbalances in these processes may result in cell failure, chromosome instability, and human disease. 
Table 1

Correlation of phenotypes between mice and humans in different settings of telomerase deficiency

\begin{tabular}{|l|l|l|l|}
\hline Mouse Genotype & Mouse Phenotype & $\begin{array}{l}\text { Phenotype on TERC-/- } \\
\text { background }\end{array}$ & Human Disease \\
\hline TERC-/- & $\begin{array}{l}\text { Late generation mice on B6 background have increase incidence of } \\
\text { cancers }\end{array}$ & DKC patients have increase risk of cancer \\
\hline$p 53-/-$ & Lymphoma and sarcomas only & $\begin{array}{l}\text { Development of breast, GI } \\
\text { adenocarcinoma, SCC. Increased } \\
\text { lymphoma }\end{array}$ & $\begin{array}{l}\text { Increased risk of sarcoma, cancers of the } \\
\text { breast, brain and adrenal gland }\end{array}$ \\
\hline K5-Trf2 & UV-induced skin cancers & $\begin{array}{l}\text { Increased incidence and } \\
\text { spontaneous skin cancers }\end{array}$ & $\begin{array}{l}\text { Increased incidence of UV-induced skin } \\
\text { cancer (Xeroderma Pigmentosum) }\end{array}$ \\
\hline Atm-/-p53-/- & T-cell lymphoma & $\begin{array}{l}\text { Increase incidence and accelerated } \\
\text { onset of T-cell lymphoma }\end{array}$ & $\begin{array}{l}\text { Increased risk of breast cancer, leukemia, } \\
\text { lymphoma }\end{array}$ \\
\hline Atm-/- & T-cell lymphoma & $\begin{array}{l}\text { Decreased incidence of T-cell } \\
\text { lymphoma }\end{array}$ & $\begin{array}{l}\text { Increased risk of breast cancer, leukemia, } \\
\text { lymphoma }\end{array}$ \\
\hline Pms-/- & $\begin{array}{l}\text { Lymphoma, sarcoma, and colon } \\
\text { cancer }\end{array}$ & $\begin{array}{l}\text { Decreased incidence off all three } \\
\text { cancers types }\end{array}$ & Hereditary non-polyposis colorectal cancer \\
\hline Cdkn2a & Lymphoma and sarcoma & $\begin{array}{l}\text { Decreased incidence off all cancers } \\
\text { types }\end{array}$ & Increase risk of multiple cancers \\
\hline E $4-M y c$ & Lymphoma & $\begin{array}{l}\text { Decreased incidence off all cancers } \\
\text { types }\end{array}$ & Burkitt lymphoma \\
\hline Apc & $\begin{array}{l}\text { Intestinal microadenomas with } \\
\text { progression to macroadenoams }\end{array}$ & $\begin{array}{l}\text { Increase incidence off } \\
\text { microadenomas with decrease } \\
\text { progression to macroadenomas }\end{array}$ & Familial adenomatous polyposis \\
\hline
\end{tabular}

